\title{
CONDIÇÃO DE EXISTÊNCIA DE UM TRIÂNGULO VIA FLUXOGRAMA: UM RELATO DE EXPERIÊNCIA
}

\section{CONDITION OF EXISTENCE OF A TRIANGLE THROUGH FLOWCHART: AN EXPERIENCE REPORT}

\author{
Juliano da Cunha da Silva ${ }^{1}$ \\ Carmen Vieira Mathias ${ }^{2}$
}

\begin{abstract}
RESUMO: Neste trabalho, apresentamos o relato de experiência de uma investigação realizada durante a aplicação de uma sequência didática que versa sobre a condição de existência de um triângulo, com enfoque em fluxogramas. Tal sequência foi implementada em uma turma de sexto ano do ensino fundamental em uma escola da rede municipal e pensada a partir das orientações existentes na Base Nacional Comum Curricular. Consideramos que o uso do material concreto foi decisivo na compreensão da condição de existência de um triângulo, conhecida a medida de três segmentos, enquanto o uso do fluxograma demonstrou-se uma opção viável no processo de ensinar e aprender o tema trabalhado.
\end{abstract}

PALAVRAS-CHAVE: Geometria. Fluxograma. Ensino e aprendizagem.

\begin{abstract}
In this work, we present the experience report of an investigation carried out during the application of a didactic sequence that deals with the condition of existence of a triangle, with a focus on flowcharts. This sequence was implemented in a sixth-year class of elementary school in a municipal school and designed based on the existing guidelines in the Common National Curriculum Base. We consider that the use of concrete material was decisive in understanding the condition of existence of a triangle, known as the three-segment measure, while the use of the flowchart proved to be a viable option in the process of teaching and learning the theme worked on.
\end{abstract}

KEYWORDS: Geometry. Flowchart. Teaching and learning.

\section{Introdução}

A carreira docente é seguida de inúmeros desafios, dentre eles, ressaltam-se os de caráter metodológico, intrínsecos a práxis diária e no âmbito de diretrizes, normas e parâmetros curriculares que servem de balizadores à Educação Básica.

Ao longo de muitos anos, a capacidade de resumir e organizar os pensamentos não era desenvolvida durante a vida escolar. Assim, o ensino da Matemática tornava-se meramente conceitual e pouco prático, sem levar em conta os efeitos do cotidiano do aluno para a resolução de problemas.

\footnotetext{
${ }^{1}$ Rede Municipal de Ensino Santa Maria, RS. E-mail: julianosilvacunha@hotmail.com

(iD) https://orcid.org/ 0000-0003-1527-5675

2 Universidade Federal de Santa Maria. E-mail: carmen@ufsm.br

(i) https://orcid.org/0000-0001-5667-159X

- Informações completas da obra no final do artigo
} 
Esse pressuposto é reforçado por Andrade (2013):

O ensino de matemática infelizmente ainda baseia-se na tradicional aula expositiva, na qual o professor reproduz para a lousa um resumo daquilo que considera importante e suficiente para que ocorra o processo de ensino e aprendizagem. Nesse modelo de ensino, o aluno apenas faz cópias dos conteúdos do quadro e tenta resolver exercícios que não passam de uma cópia daquilo que o professor resolveu no quadro (ANDRADE, 2013, p. 15-16).

Porém, observamos que, após muitos anos de pesquisas na área de ensino, desenvolvimento social e psicologia infantil, são apresentados novos cenários que demonstram a importância de o aluno ser o protagonista do próprio saber. Dessa forma, compreendemos que o pensamento matemático necessita ser desenvolvido desde os anos iniciais, valorizando o processo e o apoio às tentativas.

A Base Nacional Comum Curricular (BNCC), além de definir o conjunto de aprendizagens essenciais da Educação Básica, apresenta o ensino de Matemática como um desenvolvimento gradativo e contínuo. Por meio dessa proposta, dependendo do estímulo dado, o estudante poderá apropriar-se do conhecimento de forma significativa e prazerosa, sendo o agente ativo na construção dos saberes.

Uma das mudanças com maior impacto na prática docente, trazida pela BNCC, em termos de saberes, conteúdos e aplicações, diz respeito ao uso de fluxogramas. Esse tópico tem uma inserção no sétimo ano, no que é denominado na BNCC de "Objeto de Conhecimento - Triângulos: construção, condição de existência e soma das medidas dos ângulos internos" (BRASIL, 2018, p. 309).

Nesse viés, destacamos o papel chave que o professor desempenha, sendo este responsável por perceber as alterações necessárias, ajudar a elaborar documentos mais completos e de acordo com a realidade dos alunos. O professor possui, ainda, a incumbência de ser o agente fiscalizador da eficácia do sistema de ensino proposto. Como resultado da tríade professores, metodologias e diretrizes educacionais, surge uma gama de abordagens metodológicas que apresentam potencialidades.

Diante desse cenário, este trabalho tem como objetivo apresentar o relato de uma investigação realizada durante a aplicação de uma sequência didática que versa sobre a condição de existência de um triângulo, com enfoque em fluxogramas. 


\section{Desenvolvimento}

Este trabalho teve como pilar de fundamentação a BNCC, para que, dessa forma, a sequência desenvolvida com os estudantes atenda aos parâmetros curriculares vigentes. A BNCC é um documento normativo que define o conjunto de aprendizagens essenciais da Educação Básica e tem como objetivos superar a fragmentação das políticas educacionais e ser balizadora da qualidade da educação (BRASIL, 2018)

A BNCC apresenta o desenvolvimento das habilidades relacionadas ao objeto de conhecimento - Geometria- em cada ano de ensino, mais especificamente, a construção e a apreensão de habilidades que servem como base ao conteúdo construção e condição de existência de um triângulo.

Apesar do trabalho aqui desenvolvido focar no ensino de Geometria nos anos finais do Ensino Fundamental, consideramos ser importante desenvolver as habilidades também nos anos iniciais, por ser uma etapa decisiva na ideia que os alunos formam sobre a Matemática. As habilidades desenvolvidas nos anos iniciais devem, sempre que possível, ser lembradas e utilizadas nos anos posteriores, para que, dessa forma, os alunos consigam realizar conexões entre o que está sendo aprendido e o que já foi visto.

Além disso, a Geometria se mostra uma ferramenta muito útil na resolução de problemas e na elaboração de esquemas, conforme Fonseca e outros (2002):

[...] os conhecimentos geométricos possibilitam a elaboração de representações mais facilmente traduzíveis em recursos visuais (gráficos, diagramas, organogramas, etc.) para diversos conceitos relacionados a tais conteúdos. Dessa maneira, a Geometria surge também como um aporte relevante para a compreensão de outros campos do conhecimento. (FONSECA et al., 2002, p. 99).

Ao realizar um olhar sobre os objetos de conhecimento a serem desenvolvidos no ensino de Geometria, podemos perceber que as habilidades apresentadas pela BNCC, durante os nove anos da Educação Básica, trazem um aumento gradativo de conhecimento. Isso se evidencia pelo fato de algumas habilidades serem extremamente semelhantes a outras, diferenciando-se por uma ou duas inserções, por exemplo. Essa configuração traz a ideia de que os conteúdos estão sendo revistos ano após ano, com um acréscimo real de conhecimento. Nesse ponto, vale salientar, que tal característica nos remonta a um ensino em espiral, no qual o aluno está em constante contato com um mesmo conteúdo, mas em diferentes níveis de aprofundamento. Acreditamos que isso foi proposto para que, dessa forma, as dificuldades sejam superadas paulatinamente, possibilitando, 


\section{ENSIN@UFMS 2021}

ISSN 2525-7056

assim, ao estudante, a oportunidade de superá-las de acordo com o seu tempo de aprendizado.

Essa observação remete ao modo com que os conteúdos são abordados nos Parâmetros Curriculares Nacionais (PCN). Nesse sentido, também realizamos uma pesquisa nesse documento, acerca dos conteúdos trazidos por este trabalho. Encontramos, a partir dessa busca, três inserções do tema fluxograma. O documento menciona os fluxogramas como forma de representação e organização de dados, recurso visual adequado no auxílio de sintetização e elaboração de conclusões, bem como uma ferramenta encontrada na veiculação de informações no cotidiano (BRASIL, 1998).

Apesar de não serem encontradas relações explícitas entre a condição de existência de um triângulo, dada a medida de três segmentos, e a abordagem pelo uso de fluxogramas, acreditamos que a BNCC reitera a importância do recurso fluxograma na construção do conhecimento matemático, entendendo que esse seja necessário para o desenvolvimento cognitivo que almejamos a nossos alunos.

Assim, fica evidente a importância já trazida pelos $P C N$ e reiterada na BNCC de um ensino voltado a atividades práticas, para que o aluno seja o protagonista do saber e evolua no desenvolvimento de procedimentos e atitudes.

Ainda, pesquisas atuais apontam a importância de o aluno ser o protagonista do próprio saber. Ou seja, o professor precisa aguçar a linha de raciocínio dos estudantes, com contraexemplos, perguntas ou sugestões, para que o aluno perceba o erro. Estará contribuindo, desse modo, para a formação de um estudante investigador, questionador e reflexivo, ou seja, que assume o papel de protagonista do seu próprio conhecimento (GUIMARÃES, 2019; FERNANDES; ALVES; ARAÚJO, 2019).

\section{Procedimentos Metodológicos e Atividades Propostas}

Contexto da pesquisa

A pesquisa ocorreu nos meses de novembro e dezembro de 2019, em uma Escola Municipal localizada no interior do Rio Grande do Sul, em que o primeiro autor atua como docente. A sequência didática foi proposta a uma turma de sétimo ano, que possuía 26 alunos.

Para o primeiro momento, a turma trabalhou de forma individual e, posteriormente, em grupos de no máximo 4 alunos, escolhidos pelos próprios estudantes. Não oferecemos 
a possibilidade de fazer as atividades propostas de forma individual, pois compreendemos que o trabalho em grupo permite o surgimento de reflexões, o embate de ideias e a formulação de hipóteses que aparecem somente quando os estudantes trabalham de forma livre entre eles.

Para fins de identificação e com o intuito de preservar a identidade dos alunos, eles serão identificados por letras do alfabeto $(A, B, C, \ldots)$ e os grupos por números $(1,2,3, \ldots)$. Atividades Propostas

O processo de ensino e aprendizagem está sempre em evolução, com isso, o professor entende que seu planejamento nunca está estanque, mas em evolução contínua. Assim, as atividades que compõem a sequência proposta foram pensadas de forma a centralizar o processo na participação dos alunos. Nesse sentido, todas as atividades possuem um momento introdutório, seguido de um diálogo com a turma.

A sequência é composta por quatro atividades e teve duração de seis períodos de cinquenta minutos, iniciando com uma proposta de familiarização ao tema fluxogramas, intitulada de Atividade Zero. Nessa atividade, planejada para execução em um período de aula, o objetivo foi apresentar aos estudantes o tema em questão, assim como balizar a execução das atividades seguintes.

O trabalho teve continuidade com uma atividade prática, também planejada para um período de aula. A denominamos de Atividade Um, em que os grupos de alunos manipularam o material concreto (palitos previamente cortados em tamanhos distintos) com o objetivo de construir triângulos. Esse momento foi destinado à observação dos critérios utilizados pelos alunos e seus posicionamentos perante uma dificuldade, fato que, incentivado pelo professor, oportunizou conjecturas e hipóteses.

A terceira atividade indicada na sequência apresentada aos alunos, a qual intitulamos Atividade Dois, versou sobre uma proposta de construção via régua e compasso, tendo duração de um período de aula. Essa atividade teve por objetivo aferir o conhecimento prévio dos alunos sobre o uso dos referidos instrumentos de desenho.

A Atividade Três consistiu na escrita de um fluxograma contendo uma definição formal sobre a condição de existência de um triângulo. Assim, finalizamos a sequência didática, conectando todas as atividades anteriores, com um fechamento lógico, de tal forma que os alunos percebam a evolução e o entrelaçamento que conceitos matemáticos sofreram no processo. 


\section{Relato da experiência}

A Atividade Zero teve como objetivo apresentar aos alunos um exemplo de fluxograma, para que se familiarizassem com a escrita e a configuração deste. Entendemos tal atividade necessária, pelo fato de que muitos alunos não conheciam fluxogramas, nem fizeram uso deles. A tarefa consistia na elaboração de um fluxograma versando sobre alguma atividade do interesse de cada aluno. Esse trabalho foi realizado de forma individual, visto que cada estudante possui sua área de interesse.

Essa atividade teve dois momentos distintos. O primeiro momento foi conduzido pelo professor, quando ele apresentou um fluxograma e pontuou as características e significados dos símbolos específicos que este apresenta. Por exemplo, o retângulo (processo), que indica um determinado procedimento e suas funções e atividades; ou um losango (decisão), que mostra que uma escolha terá de ser feita e que o fluxo do processo seguirá determinada direção em função desta, entre outros. A Figura 1 ilustra o fluxograma apresentado à turma.

Figura 1. Exemplo de fluxograma apresentado aos alunos na Atividade Zero

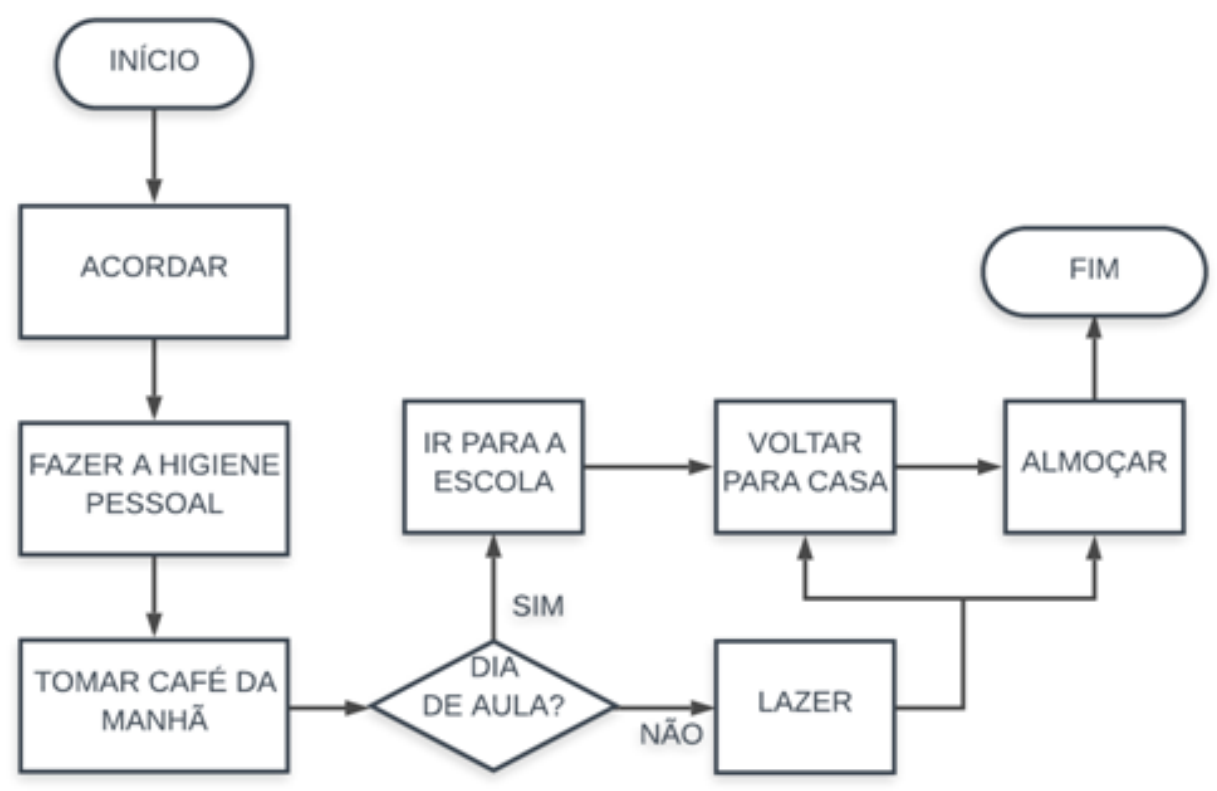

Fonte: Os autores.

Após finalizado o primeiro momento, os alunos foram desafiados a produzir o seu próprio fluxograma. $O$ resultado da atividade foi entregue na aula posterior. 
Ao lermos os fluxogramas entregues, percebemos que, de maneira geral, os alunos compreenderam a explicação realizada e como o exemplo visto em aula foi relevante na execução das tarefas. Todos os alunos elaboraram um fluxograma semanal, incluindo detalhes e decisões tomadas durante a sua produção.

A Figura 2 ilustra o fluxograma do aluno G, o qual construiu um fluxograma semanal, pontuando as questões mais relevantes do seu dia a dia.

Figura 2. Exemplo de fluxograma apresentado pelo aluno $\mathrm{G}$

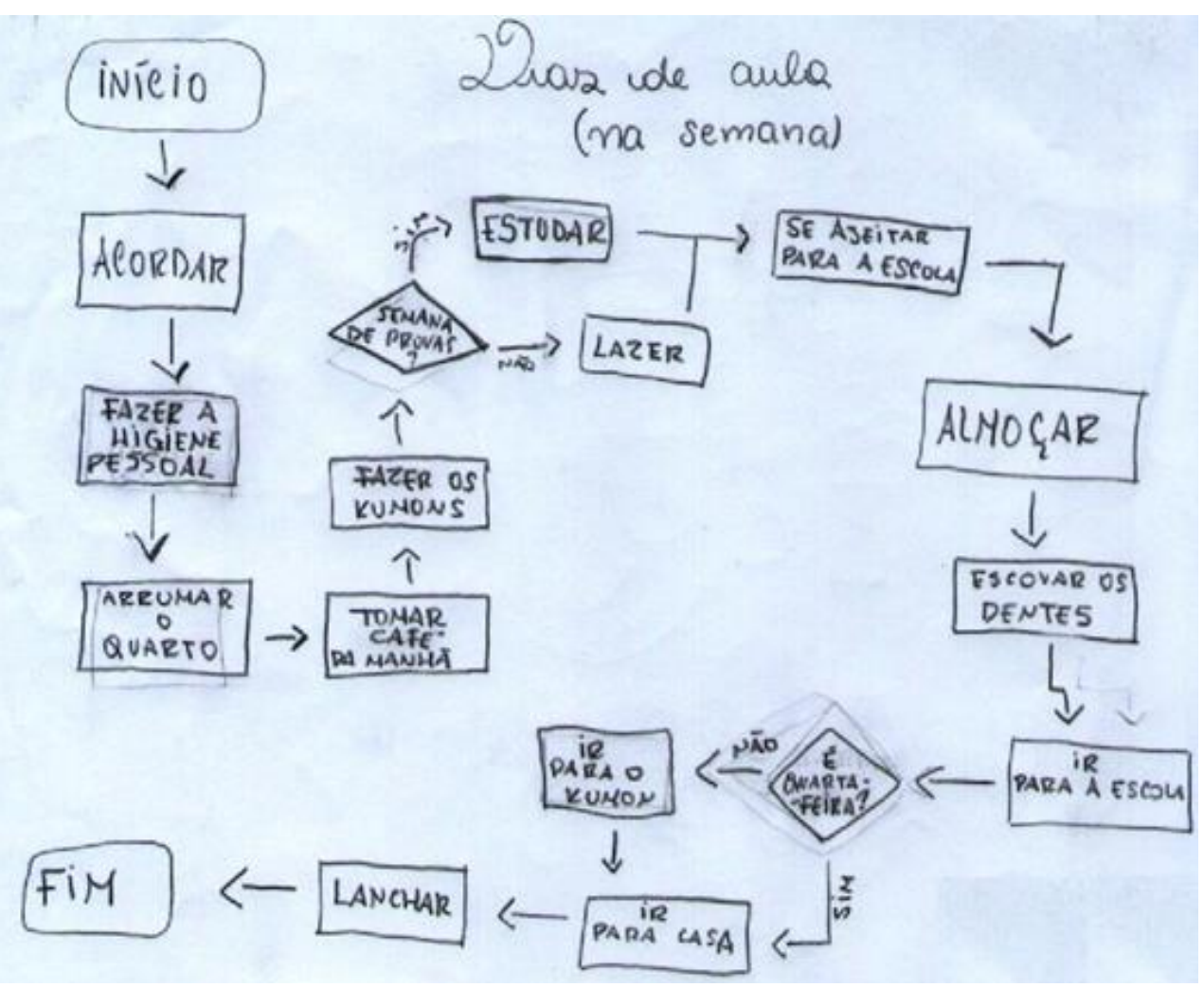

Fonte: Dados da pesquisa

Observamos que o aluno expôs decisões como, por exemplo, se a semana tinha ou não alguma prova, ou o fato de ser quarta-feira, dia em que o aluno $G$ possui uma atividade no Kumon logo após o término da aula. Percebe-se, ainda, o cuidado que esse aluno tomou quando nos referimos à centralização das setas e às formas geométricas presentes no seu fluxograma, aspecto observado pelo padrão dos retângulos e pelo desenho dos losangos, tendo em vista as marcas de borracha deixadas no papel.

$\mathrm{Na}$ sequência do trabalho, foi realizada a Atividade 1. Essa tarefa consistiu em distribuir um conjunto de 9 ou doze palitos de picolé de diferentes medidas (comprimento) aos grupos, de acordo com a quantia de alunos em cada um, para montarem triângulos. 


\section{ENSIN@UFMS 2021}

ISSN 2525-7056

Nosso objetivo com essa atividade foi que os estudantes percebessem que em determinadas configurações de três palitos não é possível formar um triângulo.

Ao receber o conjunto de palitos, os alunos, rapidamente, construíam seus triângulos, conforme o planejado. Diante de uma configuração não adequada, faziam o remanejamento necessário para a utilização de todos os palitos, como ilustra a Figura 3.

Figura 3. Alunos durante a montagem dos triângulos com material concreto
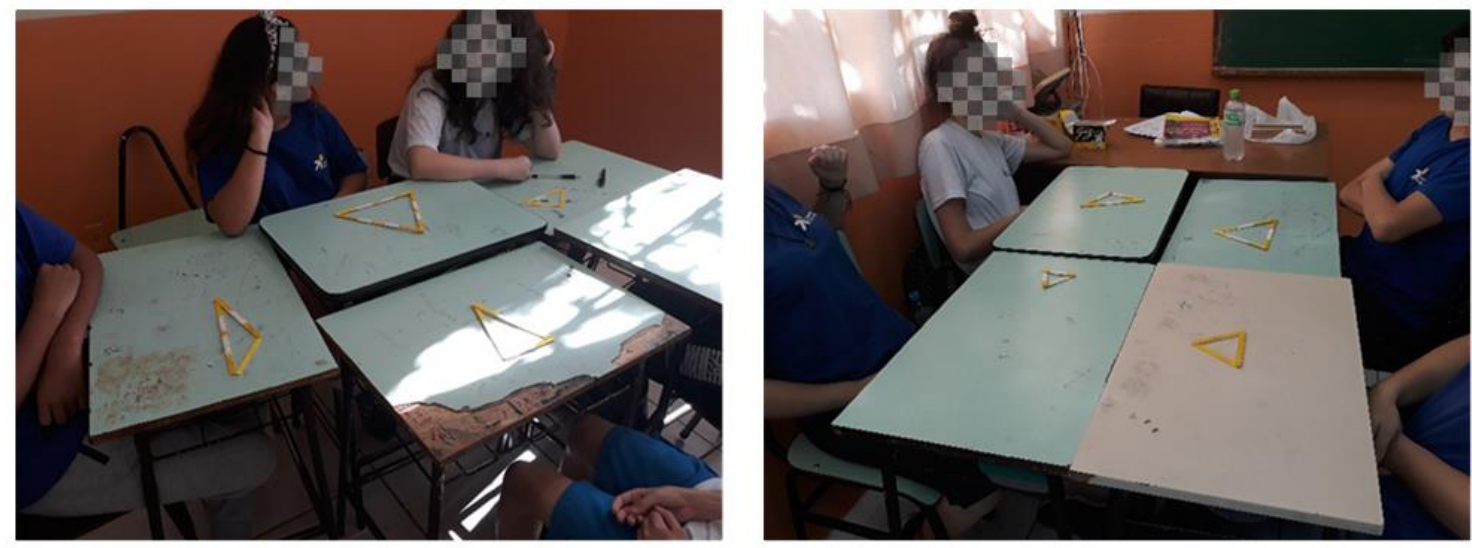

Fonte: Dados da pesquisa

Observamos que a percepção das adequações necessárias para construir o triângulo foi facilitada pelo uso de material concreto e pela possibilidade de discussão entre os alunos de cada grupo. Por uma questão de organização da turma, para que todos tivessem a oportunidade de participar, os grupos fizeram seus levantamentos e elaboraram suas justificativas separadamente. Quatro grupos justificaram a construção dos triângulos com o argumento de que possuíam um palito muito grande e dois palitos muito pequenos. Já o grupo que fez maior número de tentativas, apenas acreditava que não havia achado o modo certo de colocar os palitos, mas que talvez existisse um. Observamos que, nesse grupo, a soma das medidas de dois palitos era muito próxima da medida do terceiro palito.

$\mathrm{Na}$ aula seguinte, realizamos a Atividade 2, de forma individual, mas os alunos ainda dispostos em grupos. Para essa aula, foi solicitado que trouxessem régua, compasso ou um pedaço de cordão, além de uma folha branca sem pauta. Para dar início ao primeiro momento, foi discutido com os alunos sobre o conhecimento prévio que possuíam a respeito do uso de régua e de compasso.

Após conversar com os discentes sobre a notação de segmento de reta, convencionamos designá-lo por $\overline{A B}$, pois seus pontos extremos eram $\mathrm{A}$ e $\mathrm{B}$. Denominamos a reta suporte de $r$. Após esse momento, mostramos aos estudantes como realizar o 


\section{ENSIN@UFMS 2021}

ISSN 2525-7056

transporte do segmento, bem como que esse processo poderia ser feito seguindo uma sequência de passos. Após realizar as construções, demos continuidade à atividade inicial e propusemos aos alunos que desenhassem um triângulo de medidas $4 \mathrm{~cm}, 5 \mathrm{~cm}$ e $8 \mathrm{~cm}$. Percebemos que alguns desenharam o triângulo utilizando apenas a régua, por tentativa e erro, sendo que, em algum momento, os vértices se encontrariam e as medidas dos lados seriam as solicitadas inicialmente.

Ao finalizar a construção dos triângulos, foi dada continuidade ao segundo momento, no qual os alunos deveriam descrever os passos de construção utilizados.

Nesse momento, percebemos como um pequeno grupo pode influenciar no desenvolvimento individual de cada aluno, tanto de forma positiva quanto negativa, diante de dúvidas pertinentes ao problema proposto.

Concluída a fase descrita acima, foi oportunizado um momento em que os estudantes puderam perceber como a descrição realizada por eles foi interpretada por outras pessoas. Para isso, foi solicitado para um aluno voluntário (aluno $\mathrm{G}$ ) ir ao quadro e fazer uma construção, conforme a leitura de uma sequência de passos descritos por outro estudante (aluno L), como ilustra a Figura 4.

Figura 4. Alunos durante a montagem dos triângulos com material concreto

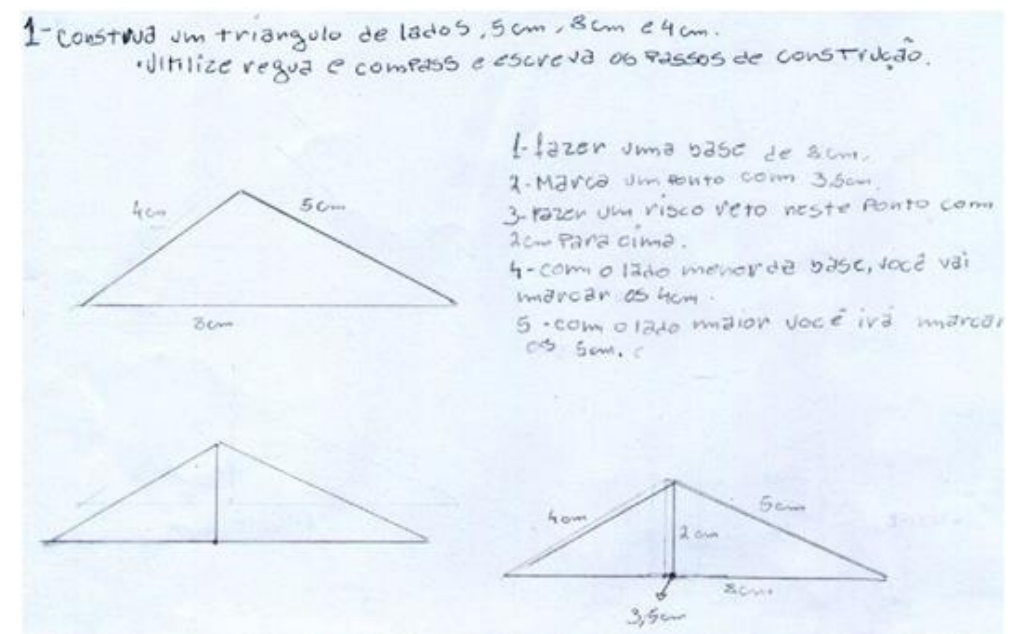

Fonte: Dados da pesquisa

Esse momento foi de extrema importância para os estudantes, pois, quando o professor leu os passos descritos pelo aluno L, o aluno $\mathrm{G}$, de imediato, manifestou que não entendeu o que era para fazer. Depois da discussão com toda a turma, os alunos perceberam como uma descrição que parece muito clara e coerente, quando lida por 
outros, pode ser confusa e incoerente, chegando a resultados distintos do que o imaginado. Ou seja, expressar de forma clara, com palavras escritas corretamente, o que se está pensando é fundamental para que outros entendam.

Assim, com base em uma notação via fluxogramas, foi solicitado aos alunos que reescrevessem os passos da construção, mas agora, seguindo as observações vistas anteriormente, como ilustra a Figura 5.

Figura 5. Reescrita dos passos de construção de um triângulo, feitos pelo aluno L, via fluxograma

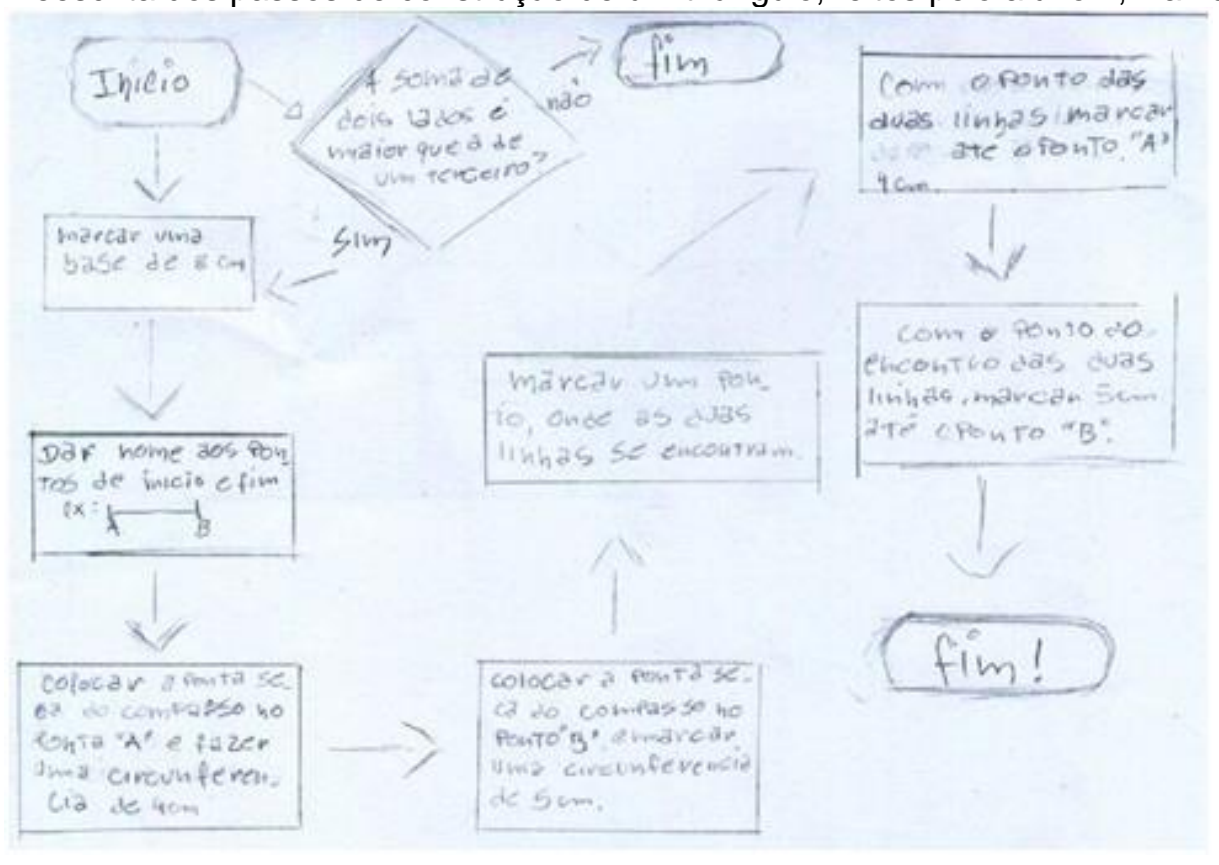

Fonte: Dados da pesquisa

Ao observarmos o fluxograma criado pelo aluno $L$ (Figura 5), fica evidente a diferença de escrita e de organização de raciocínio. Nesse exemplo, conseguimos perceber como os questionamentos e as discussões realizadas em grupo foram positivas na continuidade $e$ no aprimoramento do trabalho realizado. Nessa etapa, os alunos conseguiram perceber a evolução nos seus trabalhos.

Após a finalização da segunda atividade, seguimos com a leitura dos fluxogramas construídos pelos alunos, com o objetivo de realizar outras construções de triângulos, dada a medida de três segmentos.

Para finalizar a proposta, foi realizada a Atividade 3, também de forma individual. Nessa etapa, foram dadas as medidas de três segmentos que não possibilitavam a construção de um triângulo. Observamos que alguns alunos começavam a construção e 
percebiam que não seria possível a finalização de todos os passos do fluxograma. Assim, alguns deles lembraram da atividade feita com os palitos, conectando as duas atividades, de forma a realizar o fechamento sobre o fato estudado, ou seja, uma formalização sobre a condição de existência de um triângulo, dada a medida de três segmentos.

Os alunos adicionaram essa condição ao fluxograma já construído, que passou a obter a decisão: a soma de dois lados é maior que a do terceiro lado? Se sim, seguem-se os passos de construção; se não, as medidas dadas não formam um triângulo. Observamos, no fluxograma do aluno B, como ilustra a Figura 6, a inserção da condição de existência, bem como um cuidado na notação dos pontos referentes aos vértices do triângulo e aos componentes do compasso.

Figura 6. Fluxograma final do aluno $B$, com a observação da condição de existência de um triângulo

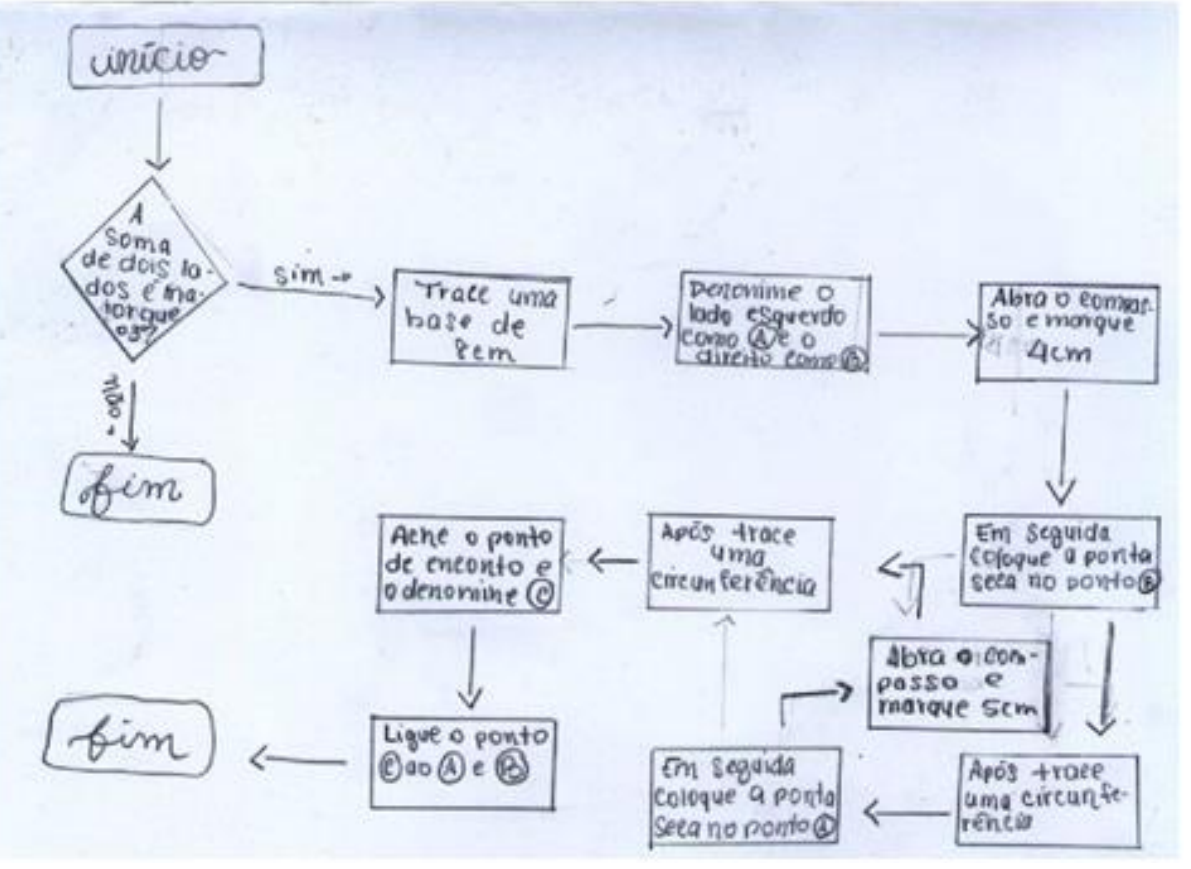

Fonte: Dados da pesquisa

Ressaltamos, ainda, que os fluxogramas possuem notações não usuais ao desenho geométrico, fato que, em termos de rigor matemático, são relevantes, de modo que devem ser trabalhados com mais afinco durante a realização das atividades. Porém, com relação à execução do trabalho e à apreensão dos conceitos tratados nessa sequência, tornam-se coadjuvantes, tendo em vista o resultado final. 


\section{Considerações Finais}

O objetivo principal deste trabalho foi apresentar o relato de uma investigação realizada ao aplicarmos uma sequência didática que versa sobre a condição de existência de um triângulo, com enfoque em fluxogramas. As atividades foram planejadas tendo o aluno como protagonista e o professor como incentivador nas tomadas de decisões.

Como os alunos não possuíam conhecimento prévio sobre fluxogramas, os exemplos e discussões foram fundamentais para despertar a curiosidade sobre o assunto, familiarizando-os com as notações básicas utilizadas. Nesse ponto, acreditamos que 0 professor, conhecendo sua turma, tenha liberdade para acrescentar mais exemplos e para modificar a atividade, de modo que ela se torne mais atrativa à sua turma.

O uso de fluxogramas se mostrou de fácil entendimento aos alunos, portanto, acreditamos ser um bom recurso na elaboração de esquemas e de resumos em atividades que necessitem uma ordem de execução. Conforme indicado pela BNCC e exposto neste trabalho, o uso de fluxogramas deve ser incentivado em diferentes contextos e anos escolares, de forma que, no decorrer da Educação Básica, o aluno sempre esteja em contato com essa possibilidade de notação em diferentes níveis de aprofundamento.

A proposta com material concreto foi bem desenvolvida e percebemos o quanto os alunos gostam de atividades de manipulação. Entendemos que esse tipo de atividade deva ser mais utilizado por nós professores, bem como que a proposta descrita neste estudo possa servir de motivação para atividades futuras. É possível considerá-la, inclusive, para a introdução de novos conteúdos, já que desperta a curiosidade e permite aos alunos serem os protagonistas na construção dos saberes.

Com a continuidade das propostas, percebemos, ainda, o incentivo no diálogo e na defesa de opinião que as atividades propiciaram, questão que acreditamos ser fundamental no desenvolvimento dos estudantes. Cumpre salientar que, mesmo sabendo o método, eles demonstram dificuldade em expor ideias e defender argumentos.

Consideramos que o uso do material concreto foi decisivo na compreensão da condição de existência de um triângulo, conhecida a medida de três segmentos, enquanto o uso do fluxograma demonstrou-se uma opção viável no processo de ensinar e aprender o tema trabalhado. 


\section{Referências}

ANDRADE, C. C. de. 0 ensino da Matemática para o cotidiano. 2013. 48f. Monografia (Especialização em Educação: Métodos e Técnicas de Ensino). Universidade Tecnológica Federal do Paraná. Medianeira, 2013. Disponível em: http://riut.utfpr.edu.br/jspui/bitstream/1/20861/2/MD_EDUMTE_2014_2_17.pdf

BRASIL. Secretaria de Educação Fundamental. Parâmetros curriculares nacionais: Matemática / Secretaria de Educação Fundamental. Brasília: MEC / SEF, p. 148, 1998.

BRASIL, Ministério da Educação. Base Nacional Comum Curricular. Brasília, 2018.

FERNANDES, C; ALVES, F. R. V; ARAÚJO, M. J. Contribuições da resolução de problemas para a formação de professores de matemática através da engenharia didática. Research, Society and Development, v. 8, n. 10, p. 1-16, 2019.

FONSECA, M. C. R, LOPES, M. P; BARBOSA, M. D. G. G; GOMES, M. L. M; DAYRELL, M. M. M. S. O ensino de Geometria na Escola Fundamental: três questões para a formação do professor dos ciclos iniciais. Belo Horizonte: Autêntica, 2002.

GUIMARÃES, G. G. Novas tendências de aprendizagem em engenharia: o aluno como protagonista na produção do conteúdo curricular na disciplina de cálculo diferencial e integral. Revista de Ensino de Engenharia, v. 38, n. 1, p.81-91, 2019.

\section{NOTAS}

\section{IDENTIFICAÇÃO DO TEXTO}

O presente texto é um recorte de Condição de existência de um triângulo: uma abordagem via fluxogramas, dissertação de Mestrado Profissional em Matemática em Rede Nacional (Profmat) apresentado na Universidade Federal de Santa Maria, em 27/02/2020, elaborada sob orientação do Professora Dra Carmen Vieira Mathias

\section{IDENTIFICAÇ̃̃O DE AUTORIA}

Juliano da Cunha da Silva. Mestre em Matemática. Professor da Rede Municipal de Ensino Santa Maria, RS, Brasil.

E-mail: julianosilvacunha@hotmail.com

(1) https://orcid.org/ 0000-0003-1527-5675

Carmen Vieira Mathias. Doutora em Matemática pela Universidade Federal de Rio Grande do Sul (UFRGS). Professora Associada da Universidade Federal de Santa Maria (UFSM), Santa Maria, RS, Brasil

E-mail: carmen@ufsm.br

(i) https://orcid.org/0000-0001-5667-159X

\section{AGRADECIMENTOS}

Não se aplica.

\section{FINANCIAMENTO}

Não se aplica. 


\section{CONSENTIMENTO DE USO DE IMAGEM}

Não se aplica.

\section{APROVAÇÃO DE COMITÊ DE ÉTICA EM PESQUISA}

Não se aplica.

\section{LICENÇA DE USO}

Autores mantêm os direitos autorais e concedem à revista ENSIN@ UFMS - ISSN 2525-7056 o direito de primeira publicação, com o trabalho simultaneamente licenciado sob a Licença Creative Commons Attribution (CC BY-NC-SA 4.0), que permite compartilhar e adaptar o trabalho, para fins não comerciais, reconhecendo a autoria do texto e publicação inicial neste periódico, desde que adotem a mesma licença, compartilhar igual.

\section{EDITORES}

Patricia Helena Mirandola Garcia, Eugenia Brunilda Opazo Uribe, Gerson dos Santos Farias.

\section{HISTÓRICO}

Recebido em: 31/08/2021 - Aprovado em: 19/10/2021 - Publicado em: 15/12/2021.

\section{COMO CITAR}

SILVA, J. C; MATHIAS, C. V. Condição de Existência de um Triângulo via Fluxograma: Um Relato de Experiência. Revista ENSIN@ UFMS, Três Lagoas, v. 2, número especial, p. 299-312. 2021. 